This is the accepted manuscript of an article by Jonathan A Hughes (j.a.hughes@keele.ac.uk), accepted for publication in the Journal of Medical Ethics. Date of acceptance 08-02-2016.

\title{
Conscientious objection in healthcare: why tribunals might be the answer
}

\author{
ABSTRACT \\ A recent focus of the debate on conscientious objection in healthcare is the question of \\ whether practitioners should have to justify their refusal to perform certain functions. A \\ recent article by Cowley addresses a practical aspect of this controversy, namely the \\ question of whether doctors claiming conscientious objector status in relation to abortion \\ should be required, like their counterparts claiming exemption from military conscription, \\ to defend their claim before a tribunal. Cowley argues against the use of tribunals in the \\ medical case, on the grounds that there are likely to be fewer unjustified claims to \\ conscientious objection in this context than in the military, and that in any case tribunals \\ will not be an effective way of distinguishing genuine and false cases. I reject these \\ arguments and propose a different conception of the role of a medical conscientious \\ objection tribunal.
}

A recent focus of the debate on conscientious objection in healthcare is the question of whether practitioners should have to provide justification for their refusal to perform certain functions. Cowley's recent article in this journal addresses a practical aspect of this controversy, namely the question of whether doctors claiming conscientious objector status should be required, like their counterparts claiming exemption from military conscription, to defend their claim before a tribunal.(1)

Cowley's focus is on conscientious refusal of doctors in the British National Health Service to facilitate abortions. Although he suggests that his argument might apply to other 
contexts, its scope is limited by reliance on certain background conditions that are far from universal even in states where abortion is legal. Cowley starts from the legal permissibility of both abortion and conscientious objection, and asks whether, given this, practitioners exercising the right of conscientious refusal should be required to present their reasons to a tribunal. His answer is that they should not. I will argue that there is a case for requiring doctors to justify their case for conscientious exemption before a tribunal, but for different reasons than the ones Cowley considers.

\section{MOTIVATIONS FOR OBJECTION AND THE NUMBER OF FALSE POSITIVES}

Cowley's argument has two strands, which share the following implicit premises:

[1] A system of conscientious objection tribunals (hereafter COTs) should only be established if the benefits of doing so exceed the costs; and

[2] The benefit of a system of COTs consists in a reduction in the number of "false positives" (i.e. cases in which exemptions from normal duties are allowed without the criteria for justified exemptions being met).

The first strand of Cowley's argument asserts that the number of false positives that would exist in the absence of COTs "would be very small, and not enough to justify the cost of running the tribunals". His argument for this rests on a disanalogy between medical and military conscientious objection.

In the military case, false positives arise where an application for exemption from conscription is motivated not by a genuine moral objection to war, but by factors such as cowardice, a desire not to be separated from loved ones, or a preference not to interrupt a civilian career. Cowley argues that similar non-moral motivations are absent, or at least much weaker, in the medical case. This part of the argument may be expressed as follows:

[3] There is little motivation for a doctor to make unjustified claims for conscientious objection. 
[4] Therefore the number of false positives in the absence of medical tribunals would be very small.

[5] Therefore the benefit of avoiding false positives would not be enough to justify the cost of running medical tribunals.

To support claim [3], Cowley addresses four possible motivations for unjustified refusal to participate in abortion discussed in the literature: doctors might seek exemption for financial reasons; for aesthetic reasons (abortions are "complex and frankly ugly"(2)); because they have "unjustified biases"; or because they have "incorrect empirical beliefs". Cowley responds with some plausibility that financial motives are unlikely in a state funded system such as the British National Health Service; ${ }^{i}$ that objections to abortion generally rest not on disputed empirical beliefs but on disputed metaphysical and moral beliefs; and that unjustified bias is a less likely motivation in the case of a General Practitioner (GP) who "is refusing to authorise abortions to anybody" than that of a civil registrar refusing to process homosexual applicants.ii His argument for the implausibility of an aesthetic motive for refusing to approve abortions warrants a fuller discussion.

As well as arguing (again, plausibly) that the "ugliness" of abortion does not apply to those undertaken in the first trimester and does not affect GPs, who are required only to sign the approval form, Cowley makes the point that in purely aesthetic terms it is hard to see why abortion should be considered uglier than other surgical interventions. To the extent that it is

\footnotetext{
i However, Minerva reports cases in Italy of conscientious objectors "who do not perform abortions in the hospitals by which they are employed, but do perform abortions in private clinics".(3) While the refusal in these cases may not have been financially motivated, it is possible that a doctor could refuse to carry out abortion within the public system in order to generate private business for himself or an associate. Cowley plays down the likelihood of such conflicting interests by describing the National Health Service as a "near-monopoly system". This, however, is inaccurate in relation to abortion. According to its own website the NHS provides fewer than $60 \%$ of abortions in some parts of the country. (http://www.nhs.uk/Conditions/Abortion/Pages/Introduction.aspx, accessed 17/12/15).

ii It is worth noting, however, that in practice the only people directly affected by a GP's refusal to authorize abortions are women, and that before the legalization of same-sex marriage in the United Kingdom a civil registrar could similarly have avoided facilitating official recognition of same-sex relationships by refusing to conduct Civil Partnership ceremonies "for anybody". Thus the possibility of describing an anti-abortion doctor's refusal in non-discriminatory terms does not rule out the possibility that discriminatory motives are present in at least some cases.
} 
perceived as uglier, the perception is likely to arise from a moral qualm about the destruction of a human-looking fetus, which "would suggest the beginning of a genuine conscientious objection".

A first response to this argument is that such a qualm is only the beginning of a genuine objection. It may well be that a negative aesthetic response to abortion is informed, consciously or otherwise, by a moral qualm. This, however, is not sufficient to justify an exemption from generally accepted professional standards and rules. In any job, a worker may be required to undertake tasks that, on balance, they judge to be wrong, but this does not automatically licence them to reject instructions or ignore rules. In order to justify noncompliance with legitimate instructions of employers, and especially with professional duties designed to protect the interests of clients, the objector's interest in following their conscience must exceed a threshold of seriousness. In Wicclair's influential account, conscientious objection is justified by the prospect of damage to the objector's integrity, involving betrayal of "core ethical values" that are "integral to her self-conception or identity" and leading to "a significant loss of selfrespect."(4) Cowley himself discusses two accounts of what makes a moral belief able to count as grounds for justified conscientious objection. On one account, similar to Wicclair's, the objector's moral belief must be "genuine" and "deep"; on the other, it must be "reasonable". On any of these criteria it is possible for doctors to have moral qualms (whether expressed in aesthetic terms or not) that could motivate them to avoid involvement in authorising or participating in abortion but which fall short of the threshold for justified conscientious objection.

A second point is that in order for conscientious objection to be ethically justified, the objector's interest in following their conscience (i.e. in avoiding the harm that may result from acting against their conscience) must be weighed against the harms to others likely to result from their failure to comply with professional norms. Even substantial damage to an objector's sense of moral integrity will not always justify breaches of norms that protect others from serious harm (for example, we would not permit doctors to withhold medically necessary blood 
transfusions however sincerely they might believe them to be morally wrong). Preventing a woman from obtaining an abortion that is legally permitted and that the health service has a duty to provide would in many cases be a serious harm. For this reason, many accounts specify as a necessary condition for conscientious objection to be justified that it should not impede patients' access to the service that the doctor is refusing to provide. This has important implications to which I will return.

Cowley's argument for claim [3] is also incomplete, in that there may be motives other than the four he considers for a doctor to falsely claim a conscientious objection to facilitating abortions. Some of these are suggested by later parts of his own argument. He notes, for example, that despite the Catholic Church's official opposition to abortion, regular churchgoing is not a reliable indicator of a genuine and deep conscientious objection to it, since many Catholics hold views on abortion opposed to those of the church. However, the churchgoing Catholic who is not personally opposed to abortion might nevertheless have strong non-moral reasons to avoid participating in professional activities linked to abortion. They might, for example, feel shame or embarrassment, or fear the disapproval of their co-religionists. In some areas doctors might also fear becoming the focus of protests or attacks from anti-abortion activists.

The arguments of the last three paragraphs show that while there may be less motivation for unjustified conscientious objection claims in medicine than in the military, the existence of such motivation cannot be dismissed. Plausible non-moral motivations include shame, embarrassment and fear of protests or attacks, and some motivations that do involve moral qualms may too weak to justify conscientious objection. Cowley's claim [4] -that there would be few false positives in the absence of tribunals - cannot, therefore, be inferred from his claim [3]. Since claim [4] is a factual claim about the situation that currently obtains in Britain (and anywhere else to which Cowley would want to extend his argument), it would, in any case, seem appropriate to seek empirical evidence rather than assert it solely on the basis of speculation about possible motives. If claim [4] is unwarranted then so too is claim [5], the 
conclusion that the benefit of avoiding false positives is not sufficient to justify the costs of running medical tribunals. But even if claim [4] were accepted, claim [5] would depend also on assessments of the harms associated with false positives, comparison of these with the costs of running tribunals, and judgement about the level of expenditure that the health service should be prepared to incur in order to prevent these harms and to ensure patients' access to the treatments to which they are entitled.

\section{ALTERNATIVE PROVISION AND THE SERIOUSNESS OF FALSE POSITIVES}

The first strand of Cowley's argument assumes that if the number of false positives is small then the benefit of reducing this number by means of COTs must also be small. This, however, depends, inter alia, on what costs are imposed by each case of unjustified conscientious objection. Cowley stipulates: "I shall assume that the objection of a particular doctor does not impede the pregnant patient's convenient access to a non-objecting doctor." If true, this assumption would make conscientious objection almost cost-free from the point of view of an individual patient. If false, it would potentially undermine the applicability of his argument in the real world.

Cowley admits that access to a non-objecting doctor "might be an issue in some remote rural parts of the UK, and it might become an issue in the future if there are too many objecting doctors." This is an important concession, since denial of convenient access to abortion may impose serious medical, psychological, social and economic risks on a pregnant woman (the kinds of risk that the 1967 Abortion Act was intended to mitigate), so even a relatively small number of such cases might justify the establishment of a system of COTs if it was likely to be effective in reducing the number of unjustified conscientious refusals. The second part of the sentence suggests that even if the harm caused by conscientious objections is low now, some kind of disincentive such as a system of COTs may be justified in order to prevent the number of unjustified refusals from rising to a level where they do cause substantial harm. 
Even with this concession, Cowley may underestimate the potential for conscientious objection to cause harms. Even if non-objecting doctors are theoretically available, there are serious questions about whether they will be accessible to women who don't know their rights or how to exercise them, or who lack transport, or who are afraid of the questions that may be asked if they are seen visiting a medical practice other than their usual one, or who have already been embarrassed by a doctor's refusal to help after overcoming their fears enough to confide in them.iii There may be harms associated with delays, especially if the pregnancy is already close to the time limit for legal abortion. Moreover, the practice of conscientious objection may have "expressive" effects that go beyond the individual patient. Picking out specific medical procedures including abortion as eligible for conscientious objection may create the impression that society regards them as morally suspect or does not fully endorse the patient's right to access them, and may therefore increase the stigma and sense of shame or guilt that may be associated with these procedures.iv

Attempting to reduce or eliminate cases of unjustified conscientious objection, whether by the use of COTs or by other means, is prima facie a worthwhile thing to do, as it will tend to reduce harms of these kinds. Even if completely successful, however, this would leave in place any harms caused by justified conscientious objection. The extent of such harm will depend on the criteria for a justified objection. As noted in the previous section, it is commonly held that a justified conscientious objection must not impede patients' access to services. On this view, the state of affairs that Cowley assumes to obtain as a matter of fact should instead be insisted upon

\footnotetext{
iii One reviewer has suggested that these harms could be reduced if the health service were to make additional efforts to inform and accommodate patients. However, even given a well-funded health service it is questionable whether all of these harms can be avoided. Some could only be rectified by means that fall outside the remit of a health service, and insofar as lack of access is caused by a shortage of doctors willing to perform abortions additional financial resources may be unable to make good the deficiency. Within a resource-limited service it is even less likely that the harms will be adequately ameliorated, and to do so would harm users of the services cut to fund these efforts.

iv McLeod provides a useful and more detailed discussion of some of the harms described in this paragraph.(5)
} 
as a condition for the justification of conscientious objection.v This condition (which I will call the no-impediment condition) most directly addresses the harms that conscientious objection directly imposes on individual patients by making services unavailable or harder to obtain; but it may also reduce its indirect, expressive harms by reasserting the patient's right to the services in question and making the right to conscientious objection subordinate to this.

Two things follow from the discussion in this section. First, accepting the noimpediment condition reinforces the conclusion of the previous section that the number of unjustified conscientious objection claims may be higher than Cowley thinks, since some cases in which the doctor has a genuine and deeply felt conscientious objection will fail to meet this condition. Second, the fact that we cannot simply assume that alternative provision is conveniently available makes the costs of false positives higher than Cowley assumes. Both these factors make it more likely that the costs of a system of COTs will be justified. I will argue in the next section that the no-impediment condition also has a bearing on the second strand of Cowley's argument, concerning the effectiveness of COTs.

\section{COWLEY ON THE EFFECTIVENESS OF TRIBUNALS}

The second strand of Cowley's argument questions whether tribunals can be an effective means of distinguishing between justified and unjustified cases of conscientious objection. The literature referred to by Cowley $(2,6-8)$ suggests two alternative accounts of what it takes for a medical conscientious objection claim to be acceptable: "the objector has to demonstrate that her beliefs are (1) 'genuine' (and deep), or that they are (2) 'reasonable'”. Neither criterion, he suggests, can be reliably assessed by a COT.

In the case of military conscientious objection, long-standing membership of one of the established "peace churches" has often been taken as sufficient evidence of a genuine and

\footnotetext{
v Cowley himself acknowledges such a condition when he writes, "given that abortion on demand is legal, and given that British doctors are allowed to conscientiously object to abortion without impeding access, should they be required to give their reasons to a tribunal?" (final emphasis added).
} 
deeply-felt belief. Cowley argues that a similar stance cannot be taken with regard to membership of the Catholic Church, because of the aforementioned fact that many Catholics disagree with their church's line on abortion. Cowley also rejects the position he attributes to Brownlee,(9) that a conscientious objector might be expected to have demonstrated commitment to their proclaimed principles through public engagement or activism; this, he argues, is too demanding and ignores the good reasons a person can have for not actively campaigning on an issue that they care about.

While it is hard to argue with Cowley's assertion that "there might be a real problem for the tribunal to reliably establish the genuineness and depth of [the beliefs of] a politically inactive applicant", it is not clear that the problem is so severe as to render COTs worthless. By engaging the objector in face-to-face discussion, a tribunal can go beyond this sort of biographically-based evidence and elicit a sense of the objector's sincerity. Of course such judgments are fallible, and might favour the more articulate, but as a society we rely on the evidential value of such face-to-face encounters in, for example, job interviews and court cases.

The idea that a justified conscientious objection must be reasonable is open to a variety of interpretations, for example that the view in question must not be based on racist or superstitious grounds, that it must be persuasive, that it must be as likely as the alternatives, or that it must be responsive to new evidence. $(6,7,10,11)$ Cowley argues that these interpretations do not readily apply to moral convictions concerning abortion, where people disagree despite the fact that "all the possible evidence is already in". He also seems to imply that an unreflective view that "abortion is obviously wrong because the fetus is 'obviously' a child" need not fail the reasonableness criterion. It is not clear whether Cowley takes these points to show that the reasonableness criterion should be rejected or that it is not the sort of criterion that could be assessed by a tribunal. I will sidestep this issue by simply accepting that, beyond the filtering out of obvious irrationality or prejudice, the reasonableness of conscientious objections cannot easily be assessed by a tribunal. 
It might seem to follow from Cowley's claims about the ineffectiveness of tribunals that they should have no role in the assessment of conscientious objection claims, and further, that those who declare themselves to have a conscientious objections should be permitted to withdraw from facilitating abortion without submitting their reasons for scrutiny. I suspect that Cowley would agree with both these conclusions, but will argue that both are mistaken.

\section{THE ROLE OF TRIBUNALS: AN ALTERNATIVE VIEW}

Cowley, as we have seen, takes as a given the legal permissibility of conscientious objection. This might seem to imply that if we lack a means of appropriately scrutinising an objector's reasons then we should just permit the objection. This permissive approach might be reasonable if we could be confident that false negatives imposed no significant harms on others. However, we have seen that this is not true. If there is no way of testing which conscientious objection claims meet the justification criteria then, depending on our assessment of the balance of harms and benefits, it might be appropriate to remove the right to conscientious objection on the basis that this is the least bad alternative. Or it might be that some way of assessing conscientious objection claims other than a tribunal is available. I will argue, however, that tribunals can have more of a role in assessing the justification of conscientious objection claims than Cowley allows.

I have argued that we cannot simply assume that the practice of conscientious objection is harmless to patients: it may directly harm women seeking abortion by making access to it more difficult, and it may have harmful expressive effects. If we believe that such harm is unjustified then its avoidance should, rather than being assumed, be one of the criteria for justified conscientious objection. I have expressed this in terms of the no-impediment condition, which would require an alternative means of obtaining abortion to be available conveniently and without imposing significant additional costs (of any kind) on the women seeking abortion. This would ensure that justified conscientious objection does not impose direct harms, although it might still have harmful expressive effects. 
I have also argued that the strength of the interest in maintaining moral integrity that a conscientious objector must have in order to justify withdrawing from the provision of a service should be weighed against the level of harm likely to be caused by that withdrawal. One way of understanding this is that there are some kinds of harm that could never be justified on the basis of conscience, but it may also be understood as requiring the objector's interest in maintaining integrity to be proportionate to the likely harm.

It follows that if the no-impediment condition is fully met then the requirement for a genuine and deeply felt belief is reduced. Less "depth" of belief is needed to justify conscientious objection, and it becomes less important that declarations of such belief are rigorously assessed. This may appear to support Cowley's view that tribunals should not be used to assess conscientious objection claims. However, the reduced importance of policing objectors' claims to be motivated by genuine and deep beliefs is contingent upon the effective enforcement of the no-impediment condition, and this is a role that tribunals can play.

This proposal would need to be worked out in more detail than can be done here, but the general idea is that before taking advantage of the right to conscientious objection, in relation to abortion or any other field in which it is permitted by law or regulation, a doctor should be required to submit for examination by a tribunal an explanation of how patients will be able to access the services from which the doctor intends to withdraw. The submission would be a generic description of proposed arrangements at the level of the doctor's practice, rather than relating to an individual patient, but would need to be sufficiently detailed to account for the range of patients (e.g. different ages, competencies and situations) and foreseeable circumstances such as the temporary absence of colleagues who would normally take over the duties that the doctor is refusing. As well as allowing for scrutiny of the proposed arrangements, the process of preparing a submission to such a tribunal would force doctors contemplating conscientious objection to think seriously about how alternative provision will work and to confront the gap between its theoretical availability and the reality of what is needed to ensure that the no-impediment condition is met. Approval from a tribunal would 
have to be sought before exercising the right of conscientious objection for the first time (perhaps with temporary arrangements for doctors joining a new practice), and when circumstances change, but might otherwise remain valid for a period of, say, five years.

Tribunals would also make assessments of the sincerity and depth of applicants' conscientious beliefs insofar as they are able, but this would be a less important aspect of their work than Cowley supposes, since demonstration of satisfactory arrangements for alternative provision would lower the threshold for this criterion. Additionally, the need to submit to a tribunal and to prepare an account of how alternative provision will be ensured will demonstrate some level of commitment (although not necessarily based on moral reasons) and may thus help to filter out frivolous claims. The reasonableness of applicants' views would not be assessed except perhaps in relation to obvious irrationality or prejudice. However, it seems to me that judgements about reasonableness (of the views themselves rather than individuals' reasons for holding them) are more appropriately situated at a higher level, where it is determined in which areas of medical practice conscientious objection will be permitted.

Although this proposal views the COT primarily as a means of preventing the harms that can arise directly from conscientious objection, it is likely that it would also reduce its indirect, expressive harms. I claimed above that the no-impediment condition may do this by subordinating the doctor's right to conscientious objection to the patient's right to the relevant services. Requiring doctors to apply for permission to withdraw from the provision of services and to show how their withdrawal is compatible with unimpeded access to those services by patients will further reinforce this, and show conscientious objection to be an exception rather than a routine practice.

It might be argued that the functions I have described not require a tribunal but could instead be achieved by a written submission evaluated by a bureaucrat. While this could go some way towards ensuring adequacy of alternative provision, there are reasons for preferring a tribunal. A face-to-face discussion would allow details of the proposed arrangements to be challenged and then explained and/or improved through dialogue, making the process more 
constructive and less bureaucratic than a wholly text-based process while also providing more of a deterrent to unjustified conscientious objection claims. A tribunal would also be betterplaced to judge the sincerity of the doctor's commitment to providing alternative arrangements and minimising any adverse impact on the patient. It would be better able than a bureaucratic application of generic guidelines to explore the effects of local conditions on the effectiveness of the proposed arrangements, especially if the panel included members of the local community. The inclusion of members of the public and potential service-users in the panel before which conscientious objection claims must be justified would also do more to counter the expressive effects of conscientious objection as described above than a purely bureaucratic process.

\section{CONCLUSION}

Cowley concludes that conscientiously objecting doctors "could understandably believe an interrogation by a tribunal to be a pointless exercise". My arguments show that this need not be the case. Tribunals can have a useful role to play in differentiating between justified and unjustified conscientious objection claims. I also claim that such a scheme would not be excessively burdensome. This needs to be judged in relation to the potential harms that the scheme is intended to avoid, which as I have argued may be substantial. The burden of explaining how alternative provision will be achieved is modest in relation to this, should not be considered excessive by those with a sincere moral commitment, and may help to deter frivolous claims.

\section{REFERENCES}

1. Cowley C. Conscientious objection and healthcare in the UK: why tribunals are not the answer. J Med Ethics. 2015 Apr 17;Published Online First: 17 April 2015. doi: 10.1136/medethics - 2015-102692.

2. Meyers C, Woods RD. An obligation to provide abortion services: what happens when physicians refuse? J Med Ethics. 1996 Apr 1;22(2):115-20.

3. Minerva F. Conscientious objection in Italy. J Med Ethics. 2014 May 26;Published Online First: 26 May 2015. doi: 10.1136/medethics - 2013-101656. 
4. Wicclair MR. Conscientious Objection in Medicine. Bioethics. 2000;14(3):205-27.

5. McLeod C. Harm or Mere Inconvenience? Denying Women Emergency Contraception. Hypatia. 2010 Feb;25(1):11-30.

6. Card RF. Conscientious Objection and Emergency Contraception. Am J Bioeth. 2007 Jun $1 ; 7(6): 8-14$.

7. Card RF. Reasonability and Conscientious Objection in Medicine: A Reply to Marsh and an Elaboration of the Reason-Giving Requirement. Bioethics. 2014 Jul 1;28(6):320-6.

8. Meyers C, Woods RD. Conscientious Objection? Yes, But Make Sure It Is Genuine. Am J Bioeth. 2007 Jun 1;7(6):19-20.

9. Brownlee K. Conscience and Conviction: The Case for Civil Disobedience. OUP Oxford; 2012. $278 \mathrm{p}$.

10. Kantymir L, McLeod C. Justification for conscience exemptions in health care. Bioethics. 2014 Jan;28(1):16-23.

11. Marsh J. Conscientious Refusals and Reason-Giving. Bioethics. 2014 Jul;28(6):313-9. 